\title{
Efficacy of Programmed Physiotherapy Rehabilitation in Pneumonectomy Patients: A Case Series
}

\author{
Simran A. Mishra ${ }^{1}$, Palak P. Darda ${ }^{1}$, Anjali S. Bais ${ }^{1}$, Neha Chitale ${ }^{2}$ and Pratik Phansopkar ${ }^{* 2}$ \\ ${ }^{1}$ Department of Cardiorespiratory Physiotherapy, Ravi Nair Physiotherapy College, \\ Datta Meghe Institute of Medical Sciences, Wardha, Maharashtra, India \\ ${ }^{2}$ Department of Musculoskeletal Physiotherapy, Ravi Nair Physiotherapy College, \\ Datta Meghe Institute of Medical Sciences, Wardha, Maharashtra, India \\ Corresponding author email: drpratik77@gmail.com
}

\section{ABSTRACT}

There are numerous causes associated with pneumonectomy like bronchial carcinoma, bronchiectasis, destroyed lung due to pulmonary tuberculosis, and many more. Pneumonectomy causes several pulmonary complications secondary to it. However, few evidences are available on effectiveness of chest physical therapy rehabilitation in reducing the complications in pneumonectomy patients. This case series reflects on effectiveness of early and routine physical therapy in preventing post-operative complications. This series includes two cases. First case was a 45 year old female who had pneumonectomy due to carcinoma. She had post-operative pain and discomfort. Second case was a53 year old male patient with pneumonectomy due to tuberculosis.He had pain, breathlessness, respiratory muscle wasting and weakness as well as abnormal postural traits after five years of pneumonectomy. Diagnosis, Intervention and outcome:Case-1:Pneumonectomy secondary to squamous cell carcinoma. Case-2: Pneumonectomy secondary to tuberculosis. Intervention includedphysical therapy, exercise and ed cation program with use of manual and mechanical devices.Outcomes included improvedmuscle strength, improved functional independency and improved Quality of Life. AprogrammedPhysiotherapy rehabilitationis effective in maintaining functional independence, improve quality of life and preventany post-opt complications.

KEY WORDS: LUNGS, PHYSIOTHERAPY, REHABILITATION PNEUMONECTOMY, BRONCHIECTASIS, CARCINOMA, FUNCTIONAL INDEPENDENCE, QUALITY OF LIFE.

\section{INTRODUCTION}

The lungs are highly dynamic intrathoracic organs. They are not only needed for gas exchange and oxygen supply, which is necessary for survival, but also play a vital role in the maintenance of physiological homeostasis and enzyme production. They are also an important part of the protection of the host against infection. They are exposed to a wide range of pathologies, both malignant and benign, which may require "Pneumonectomy (Jameset

Biosc Biotech Res Comm P-ISSN: 0974-6455 E-ISSN: 2321-4007

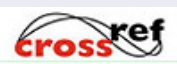

Identifiers and Pagination

Year: 2021 Vol: 14 No (6) Special Issue

Pages: $310-319$

This is an open access article under Creative

Commons License Attribn 4.0 Intl (CC-BY).

DOI: $h t t p: / / d x . d o i . o r g / 10.21786 / b b r c / 14.6 .65$ al., 1999; Mishraet al., 2020). Pneumonectomy is defined as intrapericardial or extra pericardial removal of the entire lung, without any resection of mediastinal, chest wall or diaphragmatic structure( Leoet al., 2004) There are numerous causes associated with pneumonectomy i.e bronchial carcinoma, bronchiectasis, destroyed lung due to pulmonary tuberculosis, and so on (Nieet al., 2010;Archinalet al., 2018).

Pneumonectomy has a significant effect on pulmonary function by reducing the pulmonary functional reserve and exercise potential by $35 \%$ and 23\% respectively and causing many pulmonary complications secondary to it(Archinalet al.2, 018).Patients who undergo a pneumonectomy should have long-term close follow-up evaluation in order to avoid post-operative complications( Mitsudomiet al., 1996). However, there are minimal to no evidence present which justify the effectiveness of chest physical therapy rehabilitation in context with long term

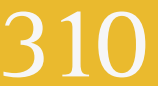


follow up as well as reduction of complication in several pneumonectomy patients. We present two unique cases of pneumonectomy with different etiology. First case helps us to know the effectiveness of early and routine physical therapy in order to avoid unnecessary postoperative complication and in the second case, patient, despite being advised for rehabilitation, he did not considered it due to some limitations and landed up in further one of the most common yet severe complication which was bronchiectasis ( Archinalet al., 2018) it made the condition worse which stand as an example for the importance and benefits of physical therapy immediate after surgery.

\section{Case 1-}

A 45 year old female, presented with the complaint of moderate breathlessness, back pain along with discomfort in chest for 3 months. She went to emergency care department with these complaints on $12 \backslash 12 \backslash 2019$. X-ray and CT scan revealed a $6 \mathrm{~cm}$ large hilar mass over the right lung. So, she underwent pneumonectomy of the right side of lung on 18/12/2019. After a week of surgery, she developed pain at surgical site which was pricking in nature and she marked 6 on NPRS scale along with some complications due to immobilization i.e. fainting and blackouts while standing (signs of orthostatic hypotension), bradycardia. So, in order to prevent the effect of immobilization as well as to increase the functional capacity, she underwent proper week-wise chest physical therapy rehabilitation.

\section{Case 2-}

A 53 year old male, farmer by occupation, presented with the complaints of chest pain, chronic cough and breathlessness since 3 months. Chest pain was insidious in onset which aggravated by deep breathing, coughing, sneezing and only relived with medications Patient marked 7 on NPRS scale by patient. Patient had cough along with expectoration with the amount of sputum production was $10 \mathrm{ml}$ and breathlessness was marked grade 3 on NYHA scale. He also has had unintentional 10-kg (22 lb) weight loss over the past 6 months. Along with these complaints, he came to rehabilitation department for further treatment on 10/08/2019. Patients past medical history included Tuberculosis and past surgical history included left lung pneumonectomy for the same condition, 5 years ago. He had 15 years history of cigarette smoking one pack per day. He used to consume alcohol occasionally.Patients general condition was ectomorphic with BMI of $18.4 \mathrm{~kg} / \mathrm{m} 2$ which comes under underweight category. Patient was completely cachexic due to extreme muscle wasting and weakness.

\section{Clinical Findings-}

\section{Case 1}

On the day one of physiotherapy rehabilitation evaluation was done.

\section{On inspection}

Chest shape: appears normal. Trachea appears slightly deviated to right side (mediastinal shift). Respiratory rate and pattern normal. Scar mark present on lateral side. Ribs appears pulled to affected side

2. On palpation: -Chest expansion was reduced at right side. Tactile vocal fremitus reduced over right side normal at right side.

3. Auscultation

a. Air entry was reduced.

b. Breath sounds appears normal.

4. Examination

a. Range Of Motion

ROM is within normal range for all extremities, limited reduction in right shoulder ROM secondary to pain

b. Muscle strength

Bilateral upper extremity strength were $4 / 5$ and lower extremity strength were 5/5 on MMRC

5. Functional independence

Require moderate to minimal assistance as per assessment with Functional Independence Measure

6. Quality of life

Significantly affected in all the domains as per assessed with RAND 36 item health survey 1.0

\section{Case 2:}

On admission, complete evaluation and assessment was done

\section{On inspection}

Appears cachectic. Chest shape: appears slightly protruded.Trachea appears slightly deviated to left side (mediastinal shift). Diminished movement of muscles of respiration. Overuse of accessory muscle were present. There was intercoastal indrawing, and chest was not bilaterally symmetrical. Suprascapular, serratus anterior, upper fibers of trapezius muscle wasting was visible. Shoulders were protracted, crowding of ribs is visible, and scoliosis deformity was visible.

2. On palpation:- Tactile vocal fremitus reduced over left side normal at right side Chest expansion was taken at nipple level was $1 \mathrm{~cm}$ which is very less than the normal valuesApex beat deviated laterally.

Table 1. Range Of Motion

\begin{tabular}{|cc|c|c|}
\hline & Right side & left side \\
\hline 1. & Shoulder flexion & $0-165$ & $0-180$ \\
\hline 2. & Shoulder extension & $0-40$ & $0-40$ \\
\hline 3. & Shoulder abduction & $0-165$ & $0-180$ \\
\hline 4. & Shoulder rotators & $0-90$ & $0-90$ \\
\hline 5. & Cervical flexion & $0-45$ & $0-45$ \\
\hline 6. & Cervical extension & $0-45$ & $0-45$ \\
\hline 7. & Cervical rotation & $0-55$ & $0-60$ \\
\hline
\end{tabular}

\section{Auscultation}

a. Air entry was absent at left and diminished in the lower lobe right

b. Breath sounds were associated with wheezes. 


\section{Examination Postural Assessment-}

Table 2. Manual Muscle Testing

\begin{tabular}{|c|c|c|}
\hline & Muscles & Gradings \\
\hline 1. & Upper fiber of trapezius & 3 \\
\hline 2. & Serratus anterior & $3-$ \\
\hline 3. & Scalene & 2 \\
\hline 4. & Pectoralis major & $2+$ \\
\hline 5. & Pectoralis minor & 3 \\
\hline 6. & Cervical flexors & 3 \\
\hline 7. & Cervical extensors & 3 \\
\hline 8. & Cervical rotators & 3 \\
\hline 9. & Shoulder flexors & $3+$ \\
\hline 10. & Shoulder extensors & $3+$ \\
\hline
\end{tabular}

a)Anterior view-Shoulders are slightly forward than normal and right shoulder was slightly elevated than left.

b) Lateral view-Neck and shoulder is slightly forward. Spine is kyphotic. Ribs and lower portion pf chest is bulged out slightly

c). Posterior view

Scoliosis is present on dorsolumbar side.

Figure 1: Case 2, images of the patients, all the findings of inspection can be seen
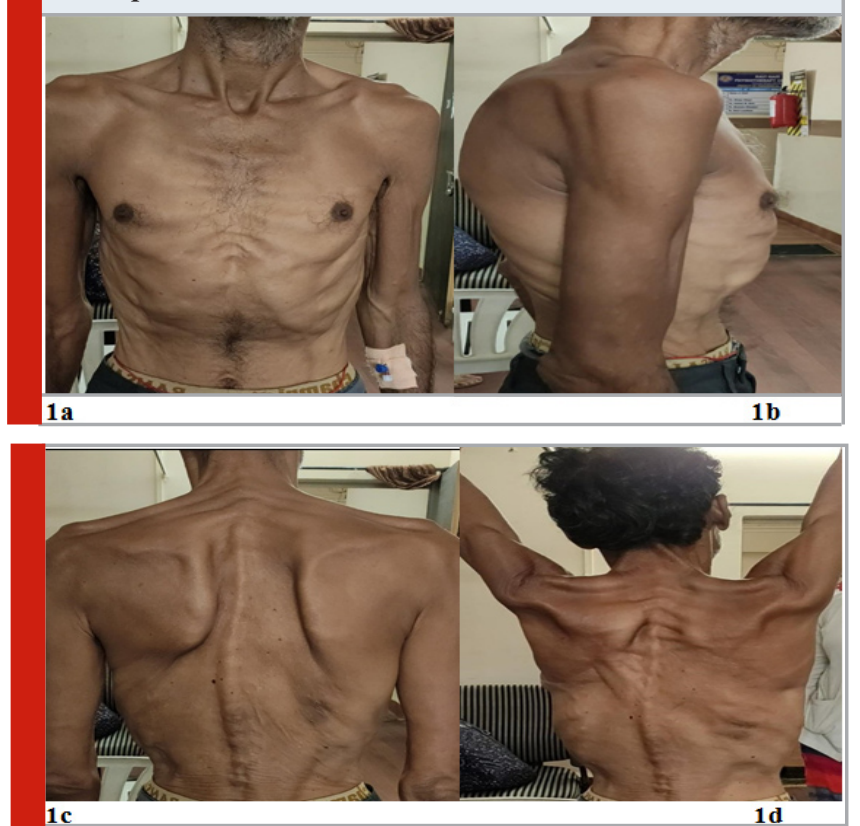

\section{Functional Independence}

Patient ambulated on an even surface 100 feet, stopped to perform purse-lip breathing in order to control her dyspnea and then ambulated for another $100 \mathrm{ft}$.

Require moderate to minimal assistance as per assessment with Functional Independence Measure.

\section{Quality of life}

Significantly affected in all the domains as per assessed with RAND 36 item health survey 1.0.

\section{Evaluation and Diagnosis}

\section{Case 1}

Patient was $45 y$ r old female referred to physiotherapy following pneumonectomy of right lung from post-opt day one.

Upon evaluation

\section{Day one}

- Pain at surgical site, pricking in nature and 6 on NPRS

- $\quad$ Restricted ROM of right shoulder joint secondary to pain, active ROM of all the remaining joint were in normal limits

- Bilateral Upper extremity strength were 4/5 and lower extremity were 5/5 on MRC

- Difficulty in bed mobility and functional independence

- Ambulation time was 2-3 mins

\section{Day eight}

- Pain was 2 on NPRS

- Very Minimal restriction of ROM

- Strength was 4/5 bilaterally in UE on MRC

- Ambulation time was more than 15 min with one flight of stairs up and down without any symptoms and rest

- 6 MWT was $450 m$

\section{Day 28}

- Pain absent

- No restriction in ROM

- Bilateral UE strength 4+/5 ON MRC

- Ambulation time and duration (30 min on level and pace, two flights of stair in one go)

- 6 MWT was 560m

Figure 2: Case 1 Chest X-Ray

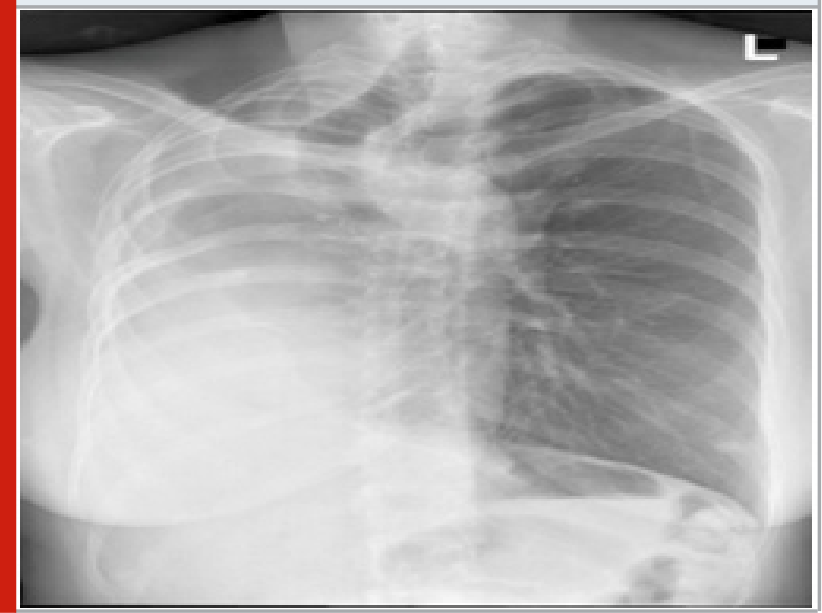

Immediate Post-Operative day 1

\section{Case 2}


Patient was 53 yr old male referred to physiotherapy, following admission in hospital for bronchiectasis

\section{Upon Evaluation \\ Day one}

- Dyspnea, grade III on NYHA

- No restriction in ROM

- Bilateral UE strength 3+/5 and LE strength 4/5 on MRC

- Impaired independence with functional transfer secondary to dyspnea

- Impaired endurance (limited ambulation)

6 MWT can’t be completed secondary to dyspnea

Day 14

- Dyspnea grade II on NYHA

- Bilateral UE strength 3+/5 and LE strength 4/5 on MRC

- $\quad$ Limited independence with functional transfer

- 6 MWT, able to complete, was 190m (vitals returned to baseline after 12 mins)

- $\quad$ Day 30

- Dyspnea grade II on NYHA

- Bilateral UE strength 3+/5 and LE strength 4/5

- Considerable independence with functional transfer

- 6 MWT, able to complete, was 240 m (vitals returned to baseline after 10 mins)

\section{Day 45}

- Dyspnea grade II on NYHA

- Bilateral UE strength $4 / 5$ and LE strength $4+/ 5$ on MRC

- Independence with functional transfer

- 6 MWT, able to complete, was $270 \mathrm{~m}$ (vitals returns to baseline after 6 mins)

It is combination of signet ring, which has got dilated bronchus in cross section represented as ring shaped opacity and its pulmonary artery represented by smaller adjacent opacit. In this study, two approaches for the plan of care has been described.

\section{A : Case 1}

This intervention has been utilized for the case 1, 45 year old female

After seven days following discharge, patient was transferred to outpatient rehabilitation before that

Detailed Evaluation and assessment is don. Symptoms, ROM, Strength, endurance (6 MWT), balance, functional independence and quality of life.

\section{Week 2-3}

To Improve ventilation for meeting increased demand Progressive spirometry, chest expansion exercises, thoracic mobility exercises in combination with UE movements, Coastal expansion. To Advance chest expansion Progressive resistive exercises (Inspiratory Muscle Training, Resisted diaphragmatic; Segmental
Breathing) Chest PNF (resisted). To Improve strength. Progressive Resistive Exercises for all the shoulder girdle and key muscles of Upper and Lower Limb, according to Delorme and Watkins protocol (sandbags, weight cuffs, therabands and free weights are utilized). To Improve and maintain postural control. Traditional Balance Exercises, 3 sets 10 repetitions or 20 mins per session, 2-3 times a week(spot marching, standing with eyes close, tandem standing, one leg standing, tandem walking, sideways walking, altering speed). To Improve Endurance, Patient was advised to walk daily for at least $30 \mathrm{~min}$ and two flight stair climbing up and down.

Figure 3: Case 2 Chest X-Ray

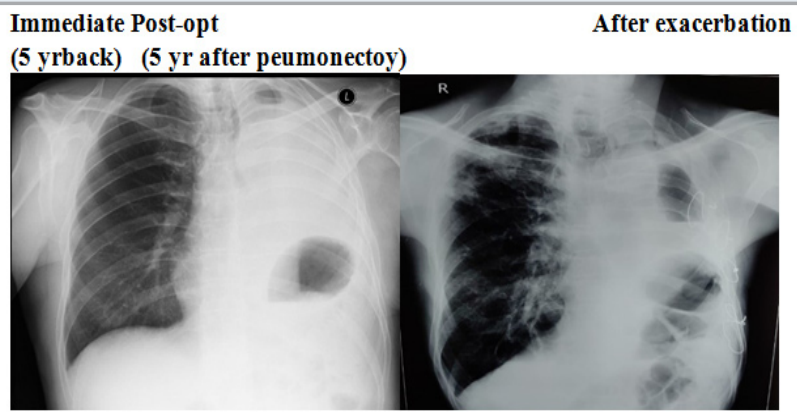

Figure 4: Case 2, CT scan (11)

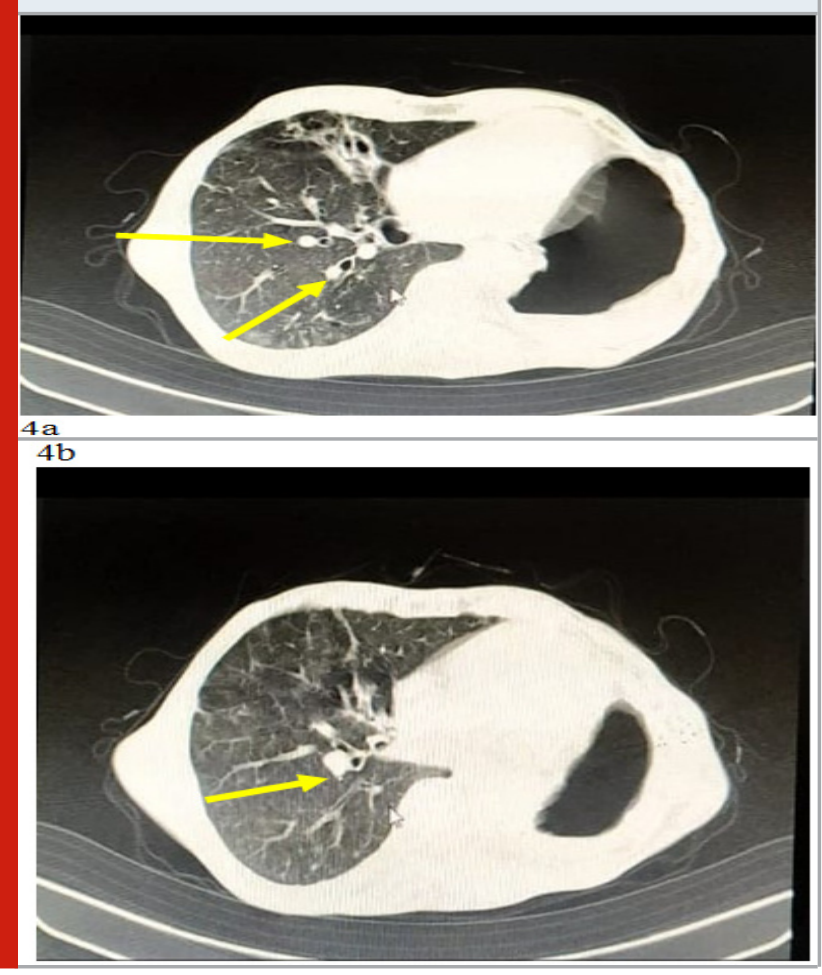

Figure 4,

( $3 a$ and $3 b$ ) are the images from case 2 of CIScan, showing signet ring sign

The signet ring is basic CI sign of bronchiectasis. 


\section{B Case-2:}

This intervention has been utilized for the case 2, 53 yearold male( Kimet al., 2011).

\section{Day 1-7}

\section{To educate patient}

Patients attitude has been neglecting and rigid towards the disease, counselling session has been given daily to make patients understanding better towards symptoms, condition, progression, future complication. Advice on lifestyle and behavioral modification especially smoking cessation. Support and reassurance.
To Alleviate Symptoms

- Dyspnea relieving positions has been taught to the patients

- (Forward lean sitting and forward bend sittings with pillow; Forward lean standing with back supported and forward bend standing with front support)

- Breath Control technique and Relaxation techniques were taught

- Pursed lip breathing exercise

- To clear secretions (bronchial hygiene therapy)

Table 3. Intervention of Case 1

\begin{tabular}{|c|c|c|c|}
\hline $\begin{array}{l}\text { Post - } \\
\text { Operative Day }\end{array}$ & Goal & Intervention & Dosage \\
\hline \multirow[t]{6}{*}{ Day 1-2 } & To Educate patient & $\begin{array}{l}\text { Lifestyle modification } \\
\text { Behavioural modification } \\
\text { Psychological support }\end{array}$ & $\begin{array}{l}\text { Daily counseling, } \\
\text { doubts and fears }\end{array}$ \\
\hline & $\begin{array}{c}\text { To Reduce } \\
\text { postoperative pain }\end{array}$ & $\begin{array}{c}\text { Relaxation, TENS at the surgical } \\
\text { site, Cryotherapy, } \\
\text { Support and Reassurance }\end{array}$ & $\begin{array}{l}\text { Four pole, burst, } 100 \mathrm{~Hz} \text {, } \\
\text { Once a day, cryo only if } \\
\text { there is no signs of fever } \\
\text { (Lanet al., 2010; } \\
\text { Benedettiet al.,1997) }\end{array}$ \\
\hline & $\begin{array}{l}\text { To Maintain and } \\
\text { regulate } \mathrm{V} / \mathrm{Q} \text { ratio } \\
\text { (matching) }\end{array}$ & $\begin{array}{l}\text { Positioning to epsilateral } \\
\text { side (pneumonectomy) } \\
\text { i.e. remaining lung } \\
\text { up, avoid supine }\end{array}$ & $\begin{array}{l}\text { Every } 2 \text { hr, 2-5 min } \\
\text { (Lanet al., 2011; } \\
\text { Lanet al., 2010) }\end{array}$ \\
\hline & $\begin{array}{c}\text { To Promote } \\
\text { airway clearance }\end{array}$ & $\begin{array}{l}\text { Postural drainage (modified) } \\
\text { and without percussion, } \\
\text { chest vibration, suctioning } \\
\text { (if unable to perform actively) }\end{array}$ & $\begin{array}{l}\text { Chest Pt every 6-8 hrs } \\
\text { (should not be painful) } \\
\text { (Andersenet al., 2017; } \\
\text { Frownfelteret al., 2014) }\end{array}$ \\
\hline & $\begin{array}{l}\text { To Prevent } \\
\text { complication }\end{array}$ & $\begin{array}{l}\text { Prophylactic DVT } \\
\text { (ankle toe movements, } \\
\text { elevation of limb), bed sores } \\
\text { (evaluation of skin, } \\
\text { positional change), upright sitting, }\end{array}$ & $\begin{array}{c}\text { Every } 2 \mathrm{hrs}, 10-20 \\
\text { mins or rps } \\
\text { (whichever suitable) } \\
\text { (Aliet al., 2017) }\end{array}$ \\
\hline & $\begin{array}{c}\text { To Monitor } \\
\text { hemodynamic changes }\end{array}$ & $\begin{array}{c}\text { Monitoring vitals } \\
\text { HR, BP, RR, Temp., Sp02 }\end{array}$ & $\begin{array}{l}\text { In supine, each time } \\
\text { after position changed }\end{array}$ \\
\hline \multirow[t]{3}{*}{ Day 3-4 } & $\begin{array}{l}\text { To Educate patient } \\
\text { and Caregiver/ family }\end{array}$ & $\begin{array}{l}\text { About treatment and outcome, } \\
\text { what is expected } \\
\text { from then, attitude of } \\
\text { family or caregiver } \\
\text { towards patient }\end{array}$ & $\begin{array}{l}\text { Counseling, guidance } \\
\text { and support }\end{array}$ \\
\hline & $\begin{array}{l}\text { To Improve lung } \\
\text { volume and ventilation } \\
\text { To Promote } \\
\text { airway clearance }\end{array}$ & $\begin{array}{c}\text { Lung expansion Therapy } \\
\text { (incentive spirometer, deep } \\
\text { breathing exercises) } \\
\text { Active Cycle of Breathing } \\
\text { Technique (ACBT), } \\
\text { Splinting and Huffing }\end{array}$ & $\begin{array}{c}10 \text { times every hour } \\
\text { when awake or } 15-20 \\
\text { min, two times a day } \\
\text { 15-20 min, two times a } \\
\text { day(Varelaet al., 2011; } \\
\text { Mejjaet al., 2020) }\end{array}$ \\
\hline & $\begin{array}{l}\text { To Improve UE } \\
\text { ROM and } \\
\text { prevent deformity }\end{array}$ & $\begin{array}{l}\text { Passive - Active Assisted } \\
\text { - Active - free exercise of UE }\end{array}$ & Once a day, $8-10 \mathrm{rps}$ \\
\hline
\end{tabular}




\begin{tabular}{|c|c|c|c|}
\hline \multirow{4}{*}{ Day 5-7 } & $\begin{array}{l}\text { To Improve } \\
\text { mobilization }\end{array}$ & $\begin{array}{l}\text { Bed mobility Activities, } \\
\text { Transfers, Thoracic mobility } \\
\text { Exercises, ambulation } \\
\text { in terms of times }\end{array}$ & $\begin{array}{l}\text { Shouldn't get hyperventilate, } \\
\text { start from } 5 \text { min progress } \\
\text { to increase by } 2 \text { min } \\
\text { each day }\end{array}$ \\
\hline & $\begin{array}{l}\text { To Improve ADLs and } \\
\text { Functional Activities }\end{array}$ & $\begin{array}{l}\text { around the ward } \\
\text { Reach outs, prehension } \\
\text { sand precision, chair sitting, } \\
\text { stationary marchs }\end{array}$ & $\begin{array}{l}\text { Pain free range } \\
\text { and no over exertion }\end{array}$ \\
\hline & $\begin{array}{l}\text { To Monitor } \\
\text { To Promote }\end{array}$ & $\begin{array}{l}\text { Signs of exertion, } \\
\text { complications, vitals } \\
\text { Bronchial hygiene therapy }\end{array}$ & $\begin{array}{l}\text { Combined responsibility } \\
\text { of patient, caregiver } \\
\text { and therapist } \\
\text { 15-20 min, two times }\end{array}$ \\
\hline & airway clearance & $\begin{array}{l}\text { (ACBT, FET, huffing and } \\
\text { effective coughing) } \\
\text { positioning in lean }\end{array}$ & $\begin{array}{l}\text { a } \operatorname{day}(\text { Varelaet al., 2011; } \\
\text { Mejjaet al., 2020) }\end{array}$ \\
\hline \multirow{8}{*}{$\begin{array}{l}\text { Day } 7 \\
\text { onwards }\end{array}$} & $\begin{array}{l}\text { To Improve lung volume } \\
\text { and ventilation }\end{array}$ & $\begin{array}{c}\text { forward in long sitting } \\
\text { Deep breathing exercises, } \\
\text { Chest expansion maneuvers, } \\
\text { thoracic mobility } \\
\text { exercise, manual devices }\end{array}$ & $\begin{array}{l}\text { (Varelaet al., 2011; } \\
\text { Aliet al., 2017) }\end{array}$ \\
\hline & $\begin{array}{l}\text { To Improve and progress } \\
\text { mobilization and ambulation }\end{array}$ & $\begin{array}{l}\text { (PEP, oscillatory devices) } \\
\text { Progressive Ambulation } \\
\text { and at higher level } \\
\text { (stairs, ramps), st, ep and } \\
\text { down unsupervised on level }\end{array}$ & $\begin{array}{l}\text { Progression } 10 \text { mins } \\
\text { onwards, ramp walking } 50 \mathrm{~m} \text {, } \\
\text { stair climbing two flights }\end{array}$ \\
\hline & $\begin{array}{l}\text { To Improve strength } \\
\text { and range of UE muscles } \\
\text { focusing mainly on shoulder }\end{array}$ & $\begin{array}{l}\text { Wall pushups, squats, PRE } \\
\text { (Biceps, Triceps, pectorals, } \\
\text { lattismusdorsi, trapezius), } \\
\text { mechanical aids }\end{array}$ & $\begin{array}{l}\text { On the basis of Delorme } \\
\text { and Watkins protocol, } \\
\text { By determining RM } \\
\text { (Varelaet al., 2011) }\end{array}$ \\
\hline & $\begin{array}{l}\text { To facilitate trunk } \\
\text { control and balance }\end{array}$ & $\begin{array}{c}\text { (sand bags, therabands), } \\
\text { ROM exercises } \\
\text { Traditional and Progressive } \\
\text { Balance Training } \\
\text { (static progress to dynamic) } \\
\text { in different postures }\end{array}$ & $\begin{array}{l}3 \text { sets per exercise, } \\
10 \text { rps per set } \\
\text { (Proctoret al., 2009) }\end{array}$ \\
\hline & $\begin{array}{c}\text { To Improve ADLs and } \\
\text { functional independence }\end{array}$ & $\begin{array}{l}\text { Incentive Spirometer, thoracic } \\
\text { mobility exercises and postural } \\
\text { control in different positions } \\
\text { (sitting, standing), leisure activities }\end{array}$ & $\begin{array}{c}\text { As much possible time } \\
\text { should be spent out of bed }\end{array}$ \\
\hline & $\begin{array}{c}\text { To Improve Postural } \\
\text { Awareness and prevention } \\
\text { of deformity (chest and spine) } \\
\text { To Monitor and prevent long }\end{array}$ & $\begin{array}{c}\text { Postural correction and } \\
\text { maintenance, bracing, } \\
\text { stretching exercises } \\
\text { Signs of DVT, fistula, }\end{array}$ & Close monitoring should \\
\hline & $\begin{array}{c}\text { term complication } \\
\text { To prepare for discharge } \\
\text { and home based rehabilitation }\end{array}$ & $\begin{array}{l}\text { deformity, new infection } \\
\text { Evaluation should be } \\
\text { done in detailed } \\
\text {-bronchial hygiene } \\
\text { - lung expansion }\end{array}$ & $\begin{array}{l}\text { be taught to patient } \\
\text { and family member as well }\end{array}$ \\
\hline & & $\begin{array}{c}\text { - mobility and ambulation } \\
\text { - ADLs and functional independence } \\
\text { - hemodynamic stability } \\
\text { - Deconditioning and desaturation } \\
\text { - Complications }\end{array}$ & \\
\hline
\end{tabular}

- Huffing and effective coughing techniques

- $\mathrm{ACBT}$ (2-3 sets as tolerated by patient twice a day)

- FET (as tolerated by patient, avoid hyperventilation, twice a day).
To improve ventilation and chest expansion( Frownfelteret al., 2014)

- Incentive Spirometer (15-20 mins, or two sets of 10 rps, whichever tolerable, twice a day) 
- Segmental Breathing Exercise

- Thoracic Mobility Exercises

- To correct posture

- $\quad$ Patient was advised to focus on maintaining correct posture in all the position

- Shoulders neutral (patient had tendency to keep shoulders protracted)

- Spine straight neck neutral (patient maintained stoop posture)

- Shoulder isometrics

- Neck isometrics

\section{Day 8-15}

- Bronchial Hygiene Therapy and Chest Expansion Therapy has been continued and progressed

- ACBT, IS and breathing exercises are continued, diaphragmatic breathing has been taught and progressed with resistance initially by therapist and later on by patient self. Respiratory Muscle training
(IMT 30 breaths in one go twice a day), Progressive inspiratory exercises with spirometer, thoracic mobility exercises

- $\quad$ Strengthening exercises and ROM exercises

- Range of motion exercises has been given for all major key muscles of UE and LE to maintain mobility and range. Strength training of all major muscle groups of bilateral uppwe and lower extremities, neck flexors and extensors, scapular muscles with more emphasis on serratus anterior and trapezius, pectorals, bicep and triceps, neck isometrics

- $\quad$ Stretching exercises

- Stretching of tighten muscles (here lattismusdorsi) were done daily with 5 second hold at end range and self-stretching was taught to patient.

- Postural exercises

- Pelvic tilt exercises in supine, abdominal press (double leg), arm and leg raises in supine, lattismus stretch self

Table 4. Outcome of Case 1

\begin{tabular}{|c|c|c|c|}
\hline Outcome Measure & Initial Evaluation & Progression (midway) & Termination \\
\hline NPRS & Six & Two & _ \\
\hline MMRC & BL UE strength $4 / 5$ & BL UE strength $4 / 5$ & BL UE strength $4+/ 5$ \\
\hline Stairs & NA & $\begin{array}{l}\text { One flight (1 x 15) } \\
\text { Unsupported }\end{array}$ & $\begin{array}{l}\text { Two flights (1 x 15) } \\
\text { Unsupported }\end{array}$ \\
\hline Total score - & $64 / 126$ & $99 / 126$ & $121 / 126$ \\
\hline Motor score - & $44 / 91$ & $69 / 91$ & $86 / 91$ \\
\hline $\begin{array}{c}\mathrm{QOL}^{*} \\
-\quad \text { Physical functioning }\end{array}$ & 35 & - & 85 \\
\hline - Role function (physical) & 25 & & 100 \\
\hline Role function (emotional) & 0 & & 100 \\
\hline Energy/fatigue & 35 & & 65 \\
\hline Emotional well being & 50 & & 76 \\
\hline Social functioning & 25 & & 75 \\
\hline Pain & 32.5 & & 77.5 \\
\hline - $\quad$ General health & 25 & & 60 \\
\hline - Health changes & 50 & & 75 \\
\hline
\end{tabular}

\section{Day 16-45}

This was part of outpatient rehabilitation as patient was discharged on 15 day The patient visited OPD and seen by therapist 4-5 times a week with per session duration of 60-90 mins Plan of care was directed towards functional limitation and independence to prevent further deterioration. Intervention aimed to strengthen UE and LE muscles and improvement in cardiovascular endurance. Strengthening exercises included elbow flexion and extension, shoulder flexion, shoulder abduction and adduction, shoulder shrugs, knee flexion and extension, hip flexion and extension, hip abduction and adduction. Exercise program was based on Delorme and Watkins protocol and progression was done according to same when patient was able to complete one cycle without symptoms.

Patient was instructed to ambulate as much as possible. Endurance exercise include stationary bicycling which was started at duration of $10 \mathrm{~min}$ without getting symptoms progressed upto approx. 20 min Balance and Gait training was also included in the intervention to improve and maintain postural awareness and control and efficient functional independence. It included exercises in progressive manner starting from static progressing to dynamic (sitting : sitting unsupported, high sitting, picking up objects, reach outs in all direction, pertubations; standing : sit to stand, standing 
with eyes close,tandem standing, one leg standing, tandem walking, sideways walking).

\section{Follow Up and Outcome \\ Case 1}

Over the duration of treatment patient was able to improve her functional independence ability and quality of life. Pain was almost absent and no restriction in range of motion as per goniometry assessment. Symptoms were alleviated and muscle strength were grossly improved in bilateral upper extremity. Ambulatory distance and time was improved and ability to transfer independently and independent self care was improved as per assessed by FIM. 6MWT distance was significantly improved by $110 \mathrm{~m}$ which is much greater than Minimally Clinical Important (MCD) distance and near to average normal range for the age group. Quality of life has been improved above mean SD reference range in all the domains except social functioning however it is near normal range.Significant improvement has seen in ROLE FUNCTIONING - physical and emotional domain. (25 to 100, 0-100 respectively).

Table 5. Outcome of Case 2

\begin{tabular}{|c|c|c|c|}
\hline Outcome Measure & Initial Evaluation & Progression (midway) & Termination \\
\hline NYHA & Grade III & & Grade II \\
\hline MMRC & $\begin{array}{l}\text { BL } \\
\text { UE strength } 3+/ 5 \\
\text { LE strength } 4 / 5\end{array}$ & $\begin{array}{l}\text { BL } \\
\text { UE strength } 3+/ 5 \\
\text { LE strength } 4 / 5\end{array}$ & $\begin{array}{l}\text { BL } \\
\text { UE strength } 4 / 5 \\
\text { LE strength } 4+/ 5\end{array}$ \\
\hline Stairs & NA & $\begin{array}{l}\text { One flight }(1 \times 15) \\
\text { With support }\end{array}$ & $\begin{array}{l}\text { Two flights }(1 \times 15) \\
\text { With support }\end{array}$ \\
\hline FIM $\quad$ Total score - & $43 / 126$ & $80 / 126$ & $98 / 126$ \\
\hline Motor score & $26 / 91$ & $56 / 91$ & $70 / 91$ \\
\hline $\begin{array}{l}\mathrm{QOL}^{*} \\
\text { - } \quad \text { Physical functioning }\end{array}$ & 0 & - & 50 \\
\hline - Role function (physical) & 0 & & 50 \\
\hline - Role function (emotional) & 0 & & 66.6 \\
\hline - Energy/fatigue & 30 & & 45 \\
\hline - $\quad$ Emotional well being & 20 & & 40 \\
\hline - $\quad$ Social functioning & 37.5 & & 62.5 \\
\hline$-\quad$ Pain & 67.5 & & 90 \\
\hline - $\quad$ General health & 35 & & 45 \\
\hline - Health changes & 25 & & 75 \\
\hline
\end{tabular}

\section{Case-2:}

Over the duration of treatment patient was able to improve his functional independence ability and quality of life. Dyspnea was reduced from grade three to two as per NYHA and muscle strength were grossly improved in bilateral upper extremity and lower extremity. Ambulatory distance and time was improved and ability to transfer independently and independent self-care was improved as per assessed by FIM. 6MWT distance was significantly improved by $80 \mathrm{~m}$ which wasn't normal or near normal to the average reference normal range for the age group but greater than Minimally Clinical Important distance. Quality of life has been improved but its not above mean SD reference range in all the domains except role functioning emotional and health change, especially significant improvement has seen in ROLE FUNCTIONING -emotional and health change domain.

\section{DISCUSSION}

Pneumonectomy has a significant effect on pulmonary function by reducing the pulmonary functional reserve and exercise potential by 35\% and 23\% respectively and causing many pulmonary complications secondary to it while long term complications includes decrement in the functional respiratory capacity, exercise tolerance, and quality of life (QOL)(Leoet al., 2004; Varelaet al., 2011). The presentation of two unique and totally opposite cases tells aboutthe effectiveness of early, programmed, evidence basedand routine physical therapy rehabilitation in maintaining functional independence and better quality of life with the avoidance of unnecessary post-op complications. Also, how the ignorance can lead to long term complications, which were otherwise preventable. Physiotherapy rehab has been addressed long back for the pneumonectomy (Ajeet et al., 2012;Dubeyet al., 2020) but its effect on functional independence and quality of life hasn't been specified yet. Few of the related studies have been reported (Ganapathi et al., 2020;30.

Agarwalet al., 2010).Here, programmed intervention has been found effective with clinically significant changes 
in 6MWT and also improved exercise tolerance. Both the patients has demonstrated improvement in functional independence and quality of lifeas well. One of the strength of the report is that both the patients were cooperative and completed rehab and attended session properly, however initially CASE 2 patient's attitude was ignorant and rigid but with education and counseling they changed and was very helpful. Limitation of the report is that duration of pneumonectomy, as one patient was immediate post opt and other has long history with long term complication so the physiological changes weren't similar for both. Also, regarding condition treatment intervention and plan of care was also different, it is suggest further research should be carried out for long term complication and effect of physiotherapy rehab on functional independence and quality of life.

\section{CONCLUSION}

Case series concluded that early, programmed and routine physiotherapy rehabilitation is effective and important in pneumonectomy patients for functional independence and quality of life and avoidance of long term, unnecessary, preventable complications.

Author's contribution: All author made best contribution for the concept, assessment and evaluation, data acquisition and analysis and interpretation of the data.

Conflict of Interest: None.

Funding Support: None.

\section{List of Abbreviation}

1. ACBT - Active Cycle of Breathing Technique

2. ADLs - Activities of Daily Living

3. DVT - Deep Vein Thrombosis

4. FET - Forced Expiratory technique

5. FIM - Functional Independence Measure

6. IMT - Inspiratory Muscle Training

7. LE - Lower Extremity

8. MCD - Minimal Clinical Difference

9. MMT - Manual Muscle Testing

10. MRC - Medical Research Council grading

11. NPRS - Numeric Pain Rating Scale

12. NYHA - Newyork Heart Association scale

13. PEP - Positive Expiratoy Pressure

14. QOL - Quality of Life

15. ROM - Range Of Motion

16. RPS - Repetitions

17. UE - Upper Extremity

18. 6 MWT - Six Minute Walk Test

\section{REFERENCES}

Acharya, S., Mahajan, S.N., Shukla, S., Diwan, S.K., Banode, P. and Kothari, N., 2010. Rheumatoid interstitial lung disease presenting as corpulmonale. Lung India: Official Organ of Indian Chest Society, 27(4), p.256. Agarwal, A., Baisakhiya, N., Kakani, A., Bhake, A., Nagrale, M. and Reddy, S., 2010. Metastatic lung cancer presenting with jugular foramen syndrome in a case of von Recklinghausens disease. Journal of cancer research and therapeutics, 6(3), p.391.

Ahmad, A.M., 2018. Essentials of physiotherapy after thoracic surgery: What physiotherapists need to know. A narrative review. The Korean journal of thoracic and cardiovascular surgery, 51(5), p.293.

Ajeet, S., Kantibhushan, C., Aniruddha, D. and Abhay, M., 2012. A Cross-Sectional Study of Effect of Smoking on Lung Functions of Spinning Mill Workers. The Anthropologist, 14(1), pp.57-60.

Ali, I., Shokri, H. and Elsayed, H.H., 2017. Prophylaxis against venous thromboembolism in thoracic surgery patients: Lack of guidelines or inappropriate implementation? Journal of the Egyptian Society of Cardio-Thoracic Surgery, 25(2), pp.147-153.

Andersen, K.S., Skoffer, B., Oestergaard, L.G., Van Tulder, M. and Petersen, A.K., 2017. The effects of respiratory physiotherapy after lung resection: Protocol for a systematic review. International journal of surgery protocols, 4, pp.1-5.

Archinal, B., 2018. Inpatient Physical Therapy Management For A Patient With Chronic Pulmonary Complications Secondary To Multiple Lobectomies: A Case Report..

Archial, B., 2018. Inpatient Physical Therapy Management For A Patient With Chronic Pulmonary Complications Secondary To Multiple Lobectomies: A Case Report.

Benedetti, F., Amanzio, M., Casadio, C., Cavallo, A., Cianci, R., Giobbe, R., Mancuso, M., Ruffini, E. and Maggi, G., 1997. Control of postoperative pain by transcutaneous electrical nerve stimulation after thoracic operations. The Annals of thoracic surgery, 63(3), pp.773-776.

Dubey, A., Ghewade, B., Lanjewar, A. and Gandhasiri, D., 2020. Lung aplasia: A rare entity presenting in adulthood. Medical Science, 24(104), pp.1822-1827.

Frownfelter, D. and Dean, E., 2014. Cardiovascular and pulmonary physical therapy-E-Book: evidence to practice. Elsevier health sciences.

Ganapathi, K., Ali, S., Jadhav, U. and Ghewade, B., 2020. A Case of Small Cell Carcinoma of Lung Presenting as Opaque Hemithorax. Journal of Clinical \& Diagnostic Research, 14(10).

Gang, N.I.E., Liu, G.J., Jean, D. and Fan, Z.M., 2010. Pneumonectomy for chronic inflammatory lung disease: indications and complications. Chinese medical journal, 123(9), pp.1216-1219.

James, T.W. and Faber, L.P., 1999. Indications for pneumonectomy. Pneumonectomy for malignant disease. Chest surgery clinics of North America, 9(2), pp.291-309.

Johnson, M.I., 2017. Post-Surgical Pain: The Status of Evidence for the Use of Transcutaneous Electrical Nerve Stimulation (TENS). AnalgResusc: Curr Res 6: 1. of, 3, p.2.

Kacprzak, G., Marciniak, M., Addae-Boateng, E., Kolodziej, J. and Pawelczyk, K., 2004. Causes and 
management of postpneumonectomyempyemas: our experience. European journal of cardio-thoracic surgery, 26(3), pp.498-502.

Kendall, F., Abreu, P., Pinho, P., Oliveira, J. and Bastos, P., 2017. The role of physiotherapy in patients undergoing pulmonary surgery for lung cancer. A literature review. Revista Portuguesa de Pneumologia (English Edition), 23(6), pp.343-351.

Kim, K.S., Byun, M.K., Lee, W.H., Cynn, H.S., Kwon, O.Y. and Yi, C.H., 2012. Effects of breathing maneuver and sitting posture on muscle activity in inspiratory accessory muscles in patients with chronic obstructive pulmonary disease. Multidisciplinary respiratory medicine, 7(1), pp.1-6.

Latchoumi, T.P., Ezhilarasi, T.P. and Balamurugan, K., 2019. Bio-inspired weighed quantum particle swarm optimization and smooth support vector machine ensembles for identification of abnormalities in medical data. SN Applied Sciences, 1(10), pp.1-10.

Lan, C.C., Chang, C.Y., Peng, C.K., Wu, C.P., Huang, K.L., Lee, S.C. and Chang, H., 2010. Effect of body positions on hemodynamics and gas exchange in anesthetized pigs shortly after pneumonectomy. Shock, 34(5), pp.482-487.

Lan, C.C., Hsu, H.H., Wu, C.P., Huang, K.L., Lee, S.C., Chang, C.Y., Peng, C.K. and Chang, H., 2011. Lateral position with the remaining lung uppermost improves matching of pulmonary ventilation and perfusion in pneumonectomized pigs. Journal of Surgical Research, 167(2), pp. e55-e61.

Leo, F., Scanagatta, P., Baglio, P., Radice, D., Veronesi, G., Solli, P., Petrella, F. and Spaggiari, L., 2007. The risk of pneumonectomy over the age of 70. A case-control study. European journal of cardio-thoracic surgery, 31(5), pp.779-782.
Mejja-Downs, A., 2012. Airway clearance techniques. In Cardiovascular and Pulmonary Physical Therapy: Evidence to Practice (pp. 309-336). Elsevier/Mosby, St. Louis, Mo.

Mishra, S.A., Darda, P.P., Bais, A.S., Chitale, N. and Phansopkar, P., 2020. Efficacy And Importance Of Programmed Physiotherapy Rehabilitation For Functional Independence And Quality Of Life In Patients Of Pneumonectomy: A Case Series. European Journal of Molecular \& Clinical Medicine, 7(11), p.2020.

Mishra, S.A., Darda, P.P., Bais, A.S., Chitale, N. and Phansopkar, P., 2020. Efficacy And Importance Of Programmed Physiotherapy Rehabilitation For Functional Independence And Quality Of Life In Patients Of Pneumonectomy: A Case Series. European Journal of Molecular \&t Clinical Medicine, 7(11), p.2020.

Mishra, S.A., Darda, P.P., Bais, A.S., Chitale, N. and Phansopkar, P., 2020. Efficacy And Importance Of Programmed Physiotherapy Rehabilitation For Functional Independence And Quality Of Life In Patients Of Pneumonectomy: A Case Series. European Journal of Molecular \&t Clinical Medicine, 7(11), p.2020.

Proctor, D.N., Fiatarone Singh, M.A., 2009. Minson CT, Nigg CR, Salem GJ, Skinner JS. American College of Sports Medicine position stand. Exercise and physical activity for older adults. Med Sci Sports Exerc. 41(7), 1510-30.

Todd, J.S., Shurley, J.P. and Todd, T.C., 2012. Thomas L. DeLorme and the science of progressive resistance exercise. The Journal of Strength \& Conditioning Research, 26(11), pp.2913-2923.

Varela, G., Novoa, N.M., Agostini, P. and Ballesteros, E., 2011, December. Chest physiotherapy in lung resection patients: state of the art. In Seminars in thoracic and cardiovascular surgery (Vol. 23, No. 4, pp. 297-306). WB Saunders. 